\title{
Negative Electrization of the Sargasso Sea as the Cause of Its Anomaly
}

\author{
Yuri Pivovarenko \\ Research and Training Centre 'Physical and Chemical Materials Science, Under Kyiv Taras Shevchenko University and NAS of Ukraine, \\ Kiev, Ukraine
}

\section{Email address: \\ y.pivovarenko@gmail.com}

\section{To cite this article:}

Yuri Pivovarenko. Negative Electrization of the Sargasso Sea as the Cause of Its Anomaly. American Journal of Electromagnetics and Applications. Vol. 8, No. 2, 2020, pp. 33-39. doi: 10.11648/j.ajea.20200802.11

Received: July 16, 2020; Accepted: July 30, 2020; Published: August 10, 2020

\begin{abstract}
Due to the daily rotation of the Earth, both its surface, including water, and the atmosphere constantly cross the lines of force of the geomagnetic field. For this reason, electromagnetic forces are constantly acting both on the earth's surface and in the earth's atmosphere. These forces distribute ground and atmospheric charges in both vertical and horizontal directions. The distributive action of the earth's electromagnetic forces is manifested in the characteristic polarization of the near-earth atmosphere and clouds, as well as in the appearance of celestial electric discharges and tornadoes. It is shown here that the same forces can cause negative electrization of the Sargasso Sea. It also shows that such negative electrization can be the cause of a number of anomalous phenomena occurring in the Sargasso Sea region, including a decrease in the buoyancy of ships sailing in the Sargasso Sea and a decrease in the lift of aircraft flying over its surface. At the same time, it is proposed here to use the positive electrization of ships sailing in the Sargasso Sea and aircraft flying over its surface to increase their buoyancy and lift, respectively. It also shows in detail the mechanism due to which the negative electrization of the Sargasso Sea air reduces the metabolic rate of the human body, in general, and, in particular, of the nervous tissue, including the brain. Thus, here is the most detailed analysis of the physical and physiological reasons that determine the anomaly of the Sargasso Sea.
\end{abstract}

Keywords: Anomaly, Sargasso Sea, Bermuda Triangle, Devil's Sea

\section{Introduction}

With the Earth's daily rotation, its surface and atmosphere continuously intersect the lines of force of the geomagnetic field (Figure 1). Therefore, all charges that are on the surface of the Earth, including water, and in the Earth's atmosphere, are constantly exposed to Lorentz forces $\mathrm{F}_{\mathrm{L}}[1,2]$ :

$$
\mathrm{F}_{\mathrm{L}}=\mathrm{q}[\mathrm{v}, \mathrm{B}]
$$

where: q-electric charge;

$\mathrm{v}$ - mainly the speed of the Earth's surface and atmosphere, in its daily rotation;

$\mathrm{B}$ - geomagnetic induction.

These Lorentz forces $F_{L}$ constantly separate positive and negative earth charges, both in the vertical and horizontal directions. So, the Lorentz force $\mathrm{F}_{\mathrm{L}}{ }^{*}$, arising from the interaction of moving ground charges with the horizontal lines of force of the geomagnetic field, directs positive charges up, and negative charges down. As a result, the upper atmosphere of the Earth acquires a positive potential of $4 \cdot 10^{5} \mathrm{~V}$ relative to the Earth's surface $[2,3]$.

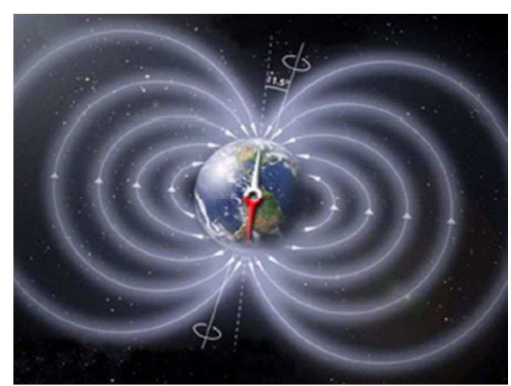

Figure 1. As the Earth has daily rotation, all objects located on its surface and in earth's atmosphere continually cross the lines of force of the geomagnetic field. The appeared Lorenz forces distribute the atmospheric and terrestrial charges. 
In addition, clouds acquire a characteristic polarization (Figure 2) due to the action of the same Lorentz force $\mathrm{F}_{\mathrm{L}}{ }^{*}[2]$.

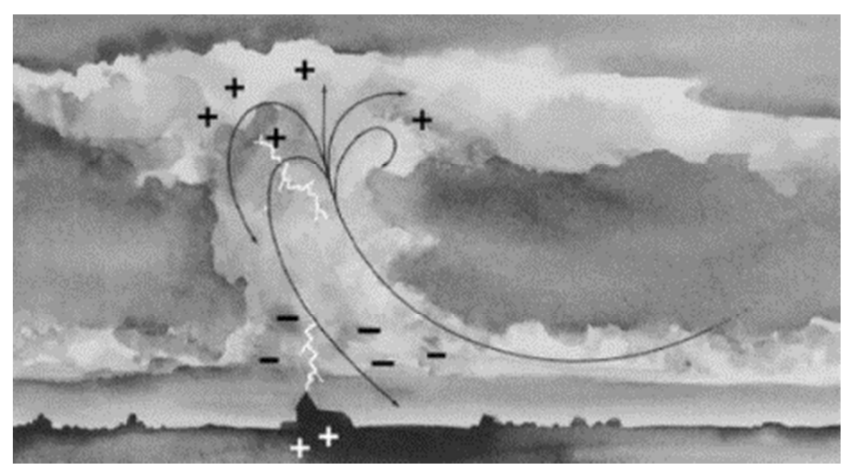

Figure 2. Polarization of clouds: the lower part of a typical cloud has a negative charge and the upper part has a positive charge [2]..

In addition, the same Lorentz force $\mathrm{F}_{\mathrm{L}}{ }^{*}$ causes the appearance of celestial discharges, both positively charged, which are directed up (Figure 3 above), and negatively charged, which are directed down (Figure 3, below) $[4,5]$.
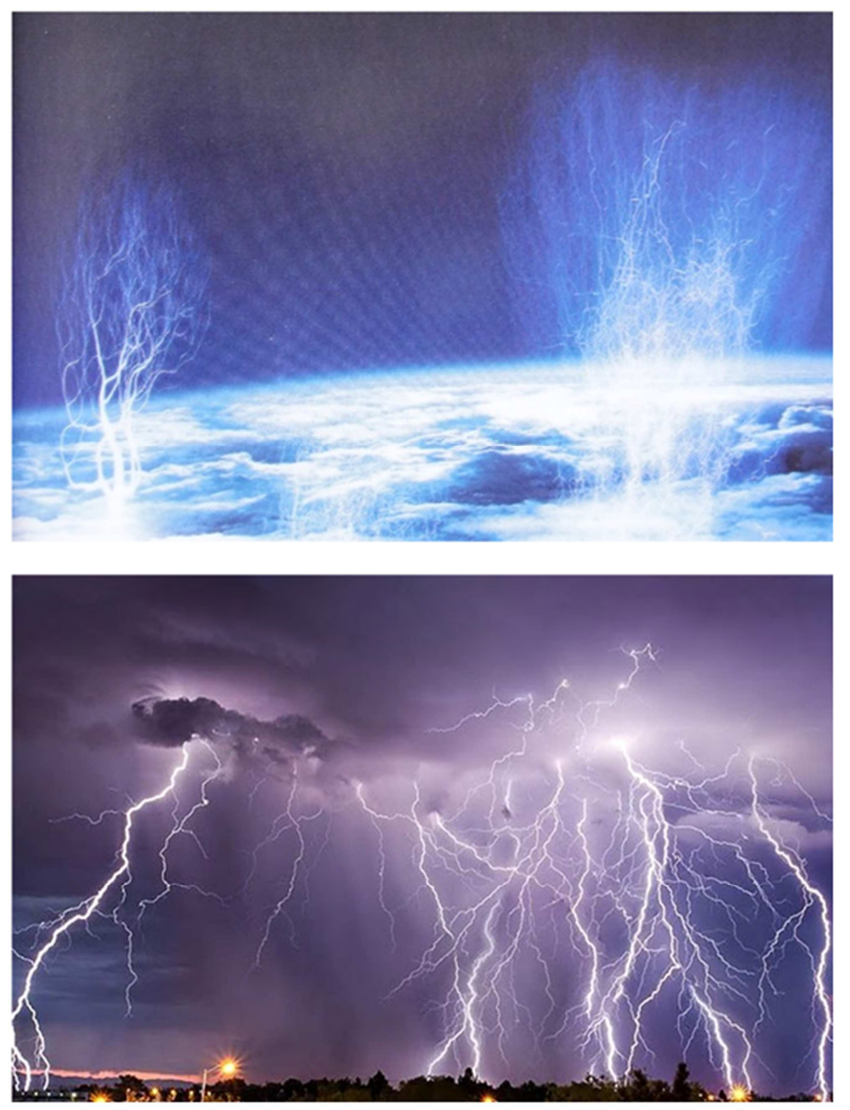

Figure 3. Above: these are blue jets representing ascending currents of hydrated protons. Below: these are ordinary lightings, which are downward flows of hydrated electrons [4, 5].

Thus, the existence of the powerful Lorentz force $\mathrm{F}_{\mathrm{L}}$, which constantly and efficiently distributes near-Earth charges in the vertical direction, as well as its direct participation in atmospheric phenomena (Figures 2, 3), is undoubted. Since this Lorentz force $\mathrm{F}_{\mathrm{L}}$ * is powerful, it is not surprising that it also affects artificial flying objects, including aircraft and balloons, increasing the lifting force of those that are positively charged and decreasing the lifting force of those that negatively charged $[6,7]$.

Thus, it is natural to assume that the same Lorentz force $\mathrm{F}_{\mathrm{L}}{ }^{*}$ can affect the buoyancy of ships, the hulls of which are usually electrified in contact with water and air. That this assumption is not far from reality is shown here. In particular, it is shown that ships crossing the Sargasso Sea, as well as other anomalous zones, including cyclonic ones, receive negative charges, which is accompanied by a decrease in their buoyancy.

Especially, it shows the effect of the Lorentz force $\mathrm{F}_{\mathrm{L}}{ }^{* *}$, arising from the interaction of horizontal water flows with vertical lines of the geomagnetic field, on the distribution of water charges in the horizontal plane. In particular, the significance of this Lorentz force for the negative electrization of the Sargasso Sea, as well as the ships crossing it, is shown. So, it is shown that the negative electrization of the inland waters of the Sargasso Sea is accompanied by a decrease in their bearing capacity with respect to objects located on the surface of the water.

It also shows why the air over the Sargasso Sea is negatively electrified and the main reason for the aviation accidents occurring over the Sargasso Sea is explained. In addition, it is shown how such a negative electrization of air over the Sargasso Sea reduces the activity of metabolism in the human body.

\section{Main Body}

\subsection{Electrization of Terrestrial and Near-Earth Objects Rotating in a Horizontal Plane}

Although this may seem surprising, all objects rotating in a horizontal plane in terrestrial conditions are electrized. Such electrization is the result of the interaction of these objects with the vertical component of the geomagnetic field. So, objects rotating counterclockwise in a horizontal plane in the northern hemisphere accumulate positive charges under the action of the Lorentz force $\mathrm{F}_{\mathrm{L}}{ }^{* *}$, which moves positive charges to the centers of these objects (Figure 4), and negative charges on their periphery.

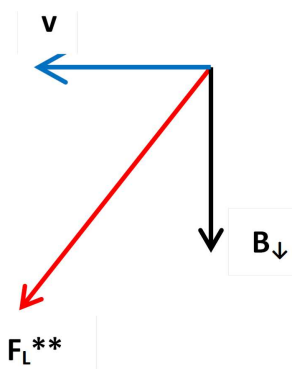

Figure 4. The Lorentz force $F_{L} * *$ (red arrow) moves positive charges to the center of the object, which rotates counterclockwise in a horizontal plane in the northern hemisphere of the Earth. This force arises due to the interaction of a moving object, the speed of which is equal to $v$, with the horizontal component of the geomagnetic field $B \downarrow$, which is directed downward. 
It was previously shown that with such rotation, it is not limited to significant positive electrization of rotating objects, but is also accompanied by the action of a powerful lifting force on them, which is actually the Lorentz force $F_{L} *$. The power of such lifting force is confirmed by the exceptional lifting ability of the tornado, namely the part of the tornado that rotates counterclockwise and causes the lifting (levitation) of captured objects (Figure 5, above) [5].

(At the same time, it should be noted that attempts to explain the tornado's lifting force, taking into account exclusively the air pressure in the zone of its action [8 - 11], seem to be futile.)

You can also see that thunderstorms, which are downwardflowing negative charges, are located on the periphery of a tornado (Figure 5, below). This clearly shows that the same Lorentz force $\mathrm{F}_{\mathrm{L}}{ }^{* *}$ (Figure 4) shifts the negative charges to the periphery of the tornado. It is also clear that these peripheral negative charges move down under the action of the Lorentz force $\mathrm{F}_{\mathrm{L}}{ }^{*}$ (blue arrows on Figure 5, above) [5]. Thus, the distribution of both types of electric charges, occurring under the influence of the same Lorentz force $\mathrm{F}_{\mathrm{L}}{ }^{* *}$ on objects rotating counterclockwise in a horizontal plane in the northern hemisphere (Figure 4), has convincing and natural confirmation (Figure 5).
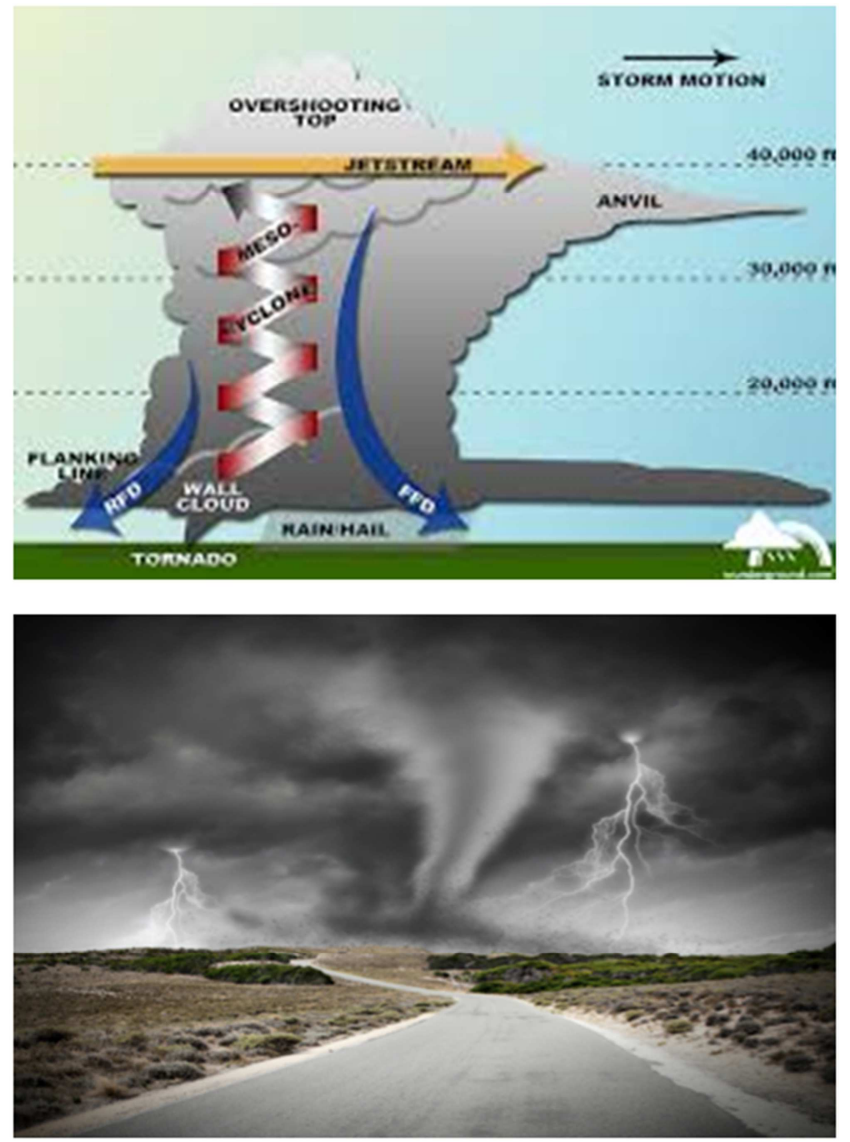

Figure 5. Above: this is a diagram illustrating both the structure of the tornado and the process of its formation: the tornado is formed from a cloud located below the horizontal air flow. Below: A typical tornado has an upward flow of positively charged air that rotates counter clockwise (when viewed from above) and is surrounded by lightning, which is a downward flow of negative charges [5].
Let us now discuss the negative electrization of objects rotating clockwise in a horizontal plane in the northern hemisphere. Obviously, the Lorentz force $\mathrm{F}_{\mathrm{L}} * *$ also acts on them, which in this case moves positive charges to the periphery of these objects, and negative charges to their centers (Figure 6).

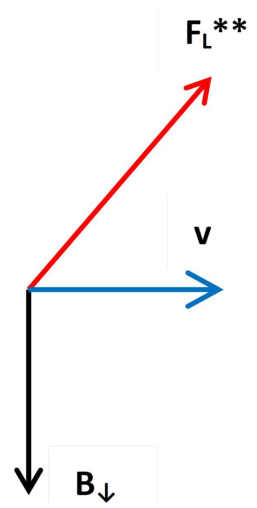

Figure 6. Lorentz force $F_{L} * *$ (red arrow) removes positive charges from the center of the object, which rotates clockwise in a horizontal plane in the northern hemisphere of the Earth. This force arises due to the interaction of such an object, whose velocity is $\boldsymbol{v}$, with the horizontal component of the geomagnetic field $B \downarrow$, which is directed downward.

For this reason, all objects rotating in this way in the northern hemisphere (Figure 6) will certainly accumulate negative charges and tend downward under the action of the Lorentz force $\mathrm{F}_{\mathrm{L}}{ }^{*}$, as well as the outer parts of the tornado (blue arrows in Figure 5 above) [5].

Let's extrapolate all this to the Sargasso Sea, as well as to the ships that sail in it.

\subsection{Negative Electrization of the Sargasso Sea}

As you can see, the Sargasso Sea is located in the northern hemisphere and is largely formed (limited) by sea currents that rotate clockwise (Figure 7).

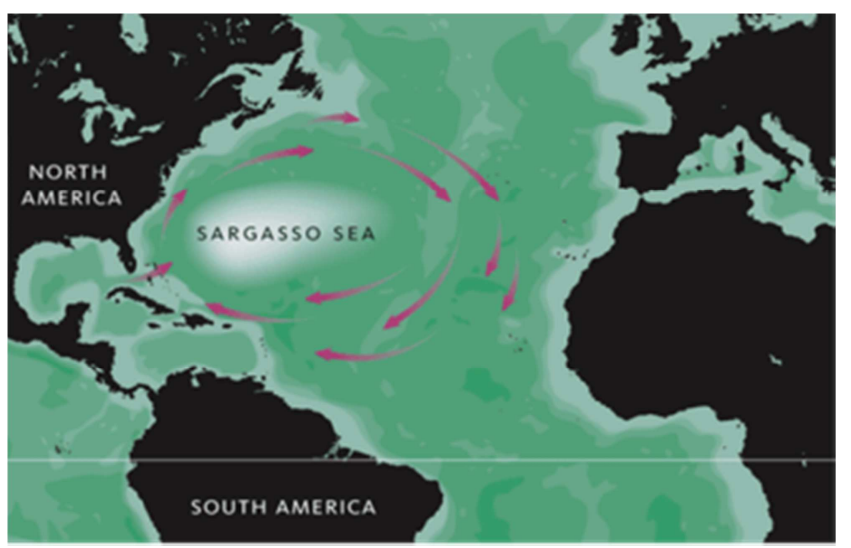

Figure 7. The Sargasso Sea is located in the Northern hemisphere of the Earth and is limited by currents moving clockwise. Equator is marked with a white horizontal line.

Air flows over the Sargasso Sea look similar.

Taking into account both of these conditions, as well as the action of the Lorentz force $\mathrm{F}_{\mathrm{L}}{ }^{* *}$ (Figure 6), it can be expected that the waters of the Sargasso Sea constantly 
accumulate negative charges. Based on the same considerations, it can be expected that positive charges are constantly removed from the Sargasso Sea. Thus, crossing the Sargasso Sea, ships leave positively charged waters and swim into negatively charged waters. It is natural to expect that these ships will receive a negative charge. This also allows us to expect that the buoyancy of ships sailing in the Sargasso Sea will decrease due to their negative electrization and the Lorentz force $\mathrm{F}_{\mathrm{L}}{ }^{*}$, which directs negatively charged objects downward. You must admit that this is already enough to suggest that the cause of shipwrecks occurring in the Sargasso Sea is the negative electrization of ships that occurs due to their contact with the negatively charged waters of the Sargasso Sea. The same assumption allows, in turn, to suggest that these shipwrecks can be prevented by the positive electrization of ships sailing in the Sargasso Sea.

\subsection{Negative Electrization of Air over the Sargasso Sea}

It is known that air flows over the Sargasso Sea have a structure that is almost identical to the structure of its sea currents (Figure 7) [12]. This contributes to the negative electrization of air over the Sargasso Sea (it is obvious that the same reason for the negative electrization of cyclones of the northern hemisphere, whose air also rotates clockwise [13]). Thus, airplanes flying over the Sargasso Sea can receive a negative charge, just like ships crossing the waters of the Sargasso Sea. Given all of the above, it can be expected that the lift of planes flying over the Sargasso Sea is lower than the lift of planes flying outside this sea. (Apparently, it is obvious that such a decrease in lift is due to the same reasons as a decrease in the buoyancy of ships sailing in the Sargasso Sea.)

All this allows us to expect that the lifting force of such aircraft can be increased due to their positive electrization [6, 7]. Thus, air accidents in the Sargasso Sea area can be prevented by positive electrization of aircraft crossing this sea.

It should be noted that negative electrization of air also affects the well-being of a person. Since this is no less important from the point of view of the topic under consideration, the mechanism of such an influence will be analyzed separately.

\subsection{Potential Dependent Nature of the Bearing Capacity of Water in Relation to Objects Placed on Its Surface}

The properties of electrified water should be analyzed more deeply, in the aspect of the topic under discussion. This is due to experimental data, which show that negative electrization of water is accompanied by a decrease in its bearing capacity in relation to objects located on its surface, in particular - in relation to ships sailing in the Sargasso Sea.

For this reason, let us first analyze some experimental results. So, it was found that starch powder does not sink in positively charged water; and "spreads" on the surface of this water for 1-2 seconds, almost completely covering it (Figure 8, left). It was also found that starch powder immediately sinks in water with negative potential (Figure 8, right) $[14,15]$.

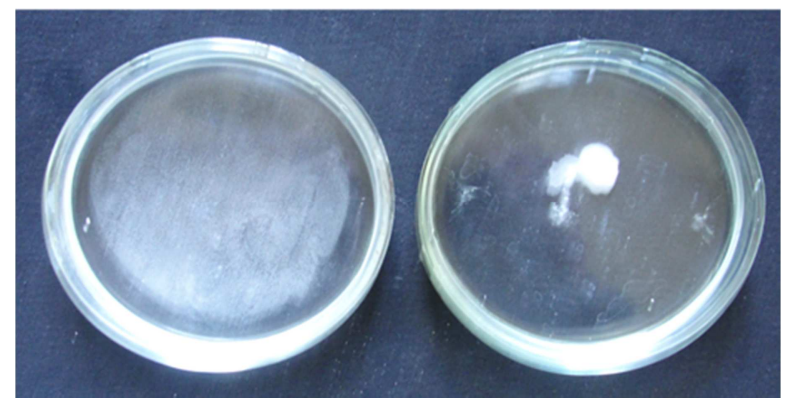

Figure 8. Left: starch powder applied to water with a potential of $+250 \mathrm{mV}$. Right: starch powder applied to water with a potential of -200 $\mathrm{mV}[14,15]$.

It was also found that $5 \mathrm{ml}$ of water with a negative potential can completely cover the bottom of the Petri dish (Figure 9, left), and $5 \mathrm{ml}$ of water with a positive potential cannot cover the same bottom - moreover, this water "shrinks" immediately after mixing (Figure 9, right). These results (Figure 9) suggest that positively charged water is more compressed a priori than negatively charged water $[14,15]$.

Salt crystals that form in oppositely charged waters have shown that this assumption is not far from reality. So, cubic or rhombic crystals that form in water with a positive electric potential (charge) (Figure 10, left), as well as needle or wood crystals that form in water with a negative electric potential (charge) (Figure 10, right)) clearly confirm this assumption $[14,15]$.

In any case, the result shown in Figure 8 allows us to draw the following conclusion: even if starch powder immediately drowns in negatively charged water (Figure 8, right), steel ships can also sink in this water.

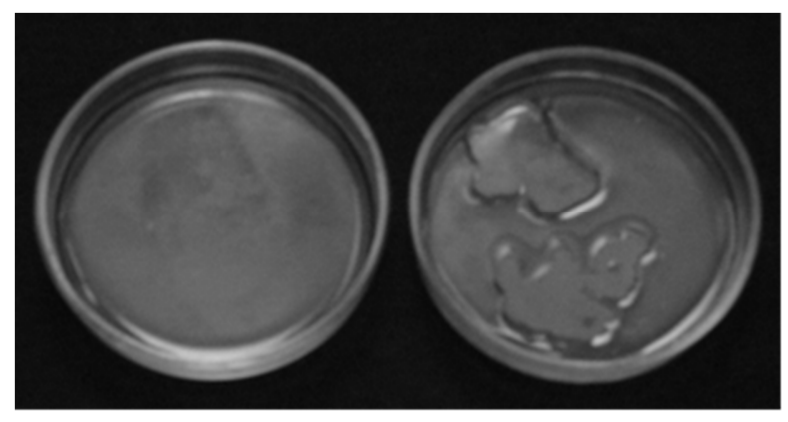

Figure 9. Left: $5 \mathrm{ml}$ of water with a potential of $-200 \mathrm{mV}$ completely cover the bottom of the Petri dish. Right: $5 \mathrm{ml}$ of water with a potential of +200 $m V$ do not completely cover the bottom of a Petri dish [14, 15].

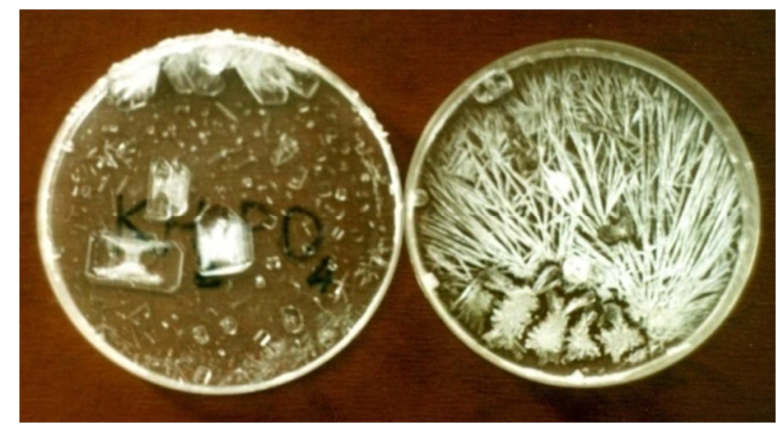

Figure 10. It is the crystals that formed after the drying of solutions of $\mathrm{KH}_{2} \mathrm{PO}_{4}$ prepared on water potentials of $+250 \mathrm{mV}$ (left) and $-250 \mathrm{mV}$ (right) $[14,15]$. 
Most likely, the presented results (Figures $8-10$ ) reflect the difference in the internal structures of positively and negatively charged waters. Most likely, this difference consists in a more "loose" packing of molecules of negatively charged water and a denser packing of molecules of positively charged water. Thus, crossing the Sargasso Sea, ships emerge from waters whose molecules are more densely packed and enter water whose molecules are less densely packed. Whatever it was, but it can also be the reason for the decrease in the buoyancy of ships sailing in the Sargasso Sea.

In addition, the results presented (Figures $8-10$ ) also allow us to conclude that a positive electrization of the water surrounding the vessel can increase their buoyancy.

\subsection{Negative Electrization of Air over the Sargasso Sea and Its Effect on Human Metabolism}

Given that the human body is constantly surrounded by air, it is useful to analyze how the electrization of air, especially negative, affects the metabolism in the human body. So, extrapolation of the presented results (Figures $8-10$ ) to the human body allows us to expect that negatively charged air of the Sargasso Sea helps to reduce skin tone and, as a result, blood vessels. Accordingly, it can help lower blood pressure. Thus, the blood supply to the brain, which is the highest located organ of a standing and seated person, will decrease in contact with the negatively charged air of the Sargasso Sea in the first place. Thus, the air of the Sargasso Sea reduces the activity of processes occurring in the human brain and contributes to the inhibition of human nervous activity, at least drowsiness.

But the effect of negatively charged air on a person can have deeper physiological foundations. To understand this, it should first be taken into account that the human intestine is constantly in contact with gaseous hydrogen (the proportion of hydrogen gas in the intestinal gas of a person varies from 20 to $34 \%$, vol. [16]), and human skin is in contact with air. For this reason, the human body can be represented as an air-hydrogen electrochemical cell, the electric field of which is directed from the surface of the skin into the intestine (Figure 11) [17].

Let us discuss the possible effect of the described electric field on the digestion processes of a person as a whole and, especially, on a person's cellular metabolism. It is known that most nutrients that enter the intestine or are formed in it have or acquire an anionic nature: fatty and organic acids, amino acids (at $\mathrm{pH} \sim 8$ ), glucose phosphate [17]. The anionic nature of nutrients is very important for their transfer into the blood, because of the influence on them of the mentioned electric field that exists between the intestine and the skin (Figure 11). Since positive electrization of the skin increases this field, and negative electrization of the skin reduces it, it can be expected that negatively charged air of the Sargasso Sea reduces both this transport and the metabolism of human cells, including nerve cells.

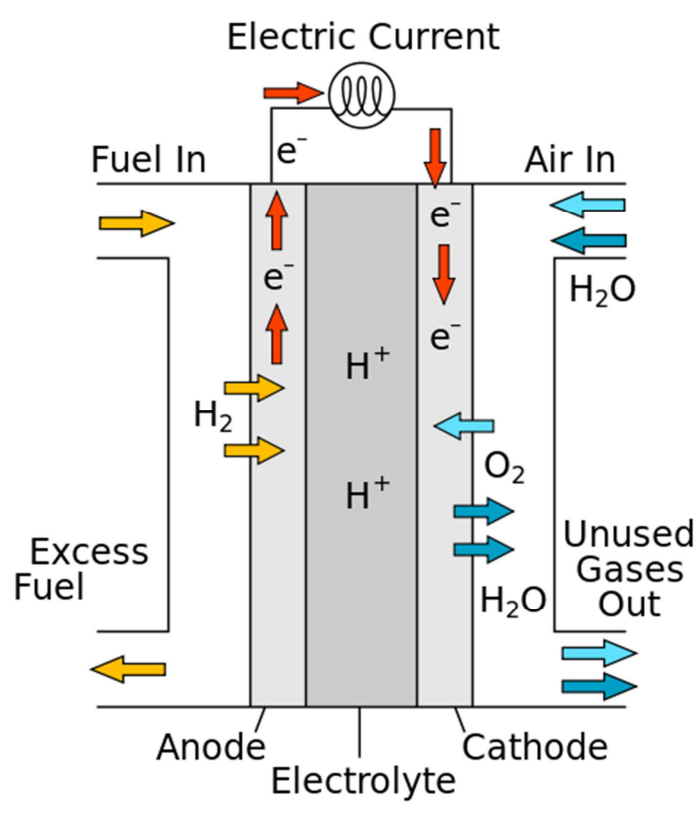

Figure 11. This is the scheme of an air-hydrogen electrochemical cell. Red arrows indicate the movement of electrons from the compartment with an aqueous solution saturated with hydrogen gas, into the compartment with an aqueous solution saturated with air.

Anionic nutrients can also travel from the intestine in contact with hydrogen gas to the surface of the skin in contact with air [17].

Given all this, it is not surprising that negatively charged air of the Sargasso Sea can cause nervous disorders in humans, which also contributes to aviation and maritime accidents.

\subsection{Natural Factors Affecting the Electrization of the Sargasso Sea}

Finally, it is useful to mention some natural factors that affect the electrization of the environment.

Light. So, it is known that the Pointing vector determines not only the direction of light rays, but also the direction of motion of positive charges [18]. This suggests that well-lit objects charge more positively than objects that are dimly lit or not at all lit. It also suggests that darkness contributes to the negative electrization of objects.

Polarization of the Earth's surface. It was previously shown that the daytime part of the Earth is electrified more positively than the nighttime part of the Earth. It was also shown that such a polarization of the Earth exists due to the orbital motion of the Earth relative to the lines of force of the magnetic field of the Sun [19]. All this allows us to conclude that ground objects are more positively electrified during the day than at night, and also that night contributes to the negative electrization of objects.

Downdrafts of air. Since the Sargasso Sea stretches from 23 to $35^{\circ} \mathrm{N}$, its air has an additional source of negative electrization. This source is air currents that descend to $30^{\circ} \mathrm{N}$ (Figure 12). 


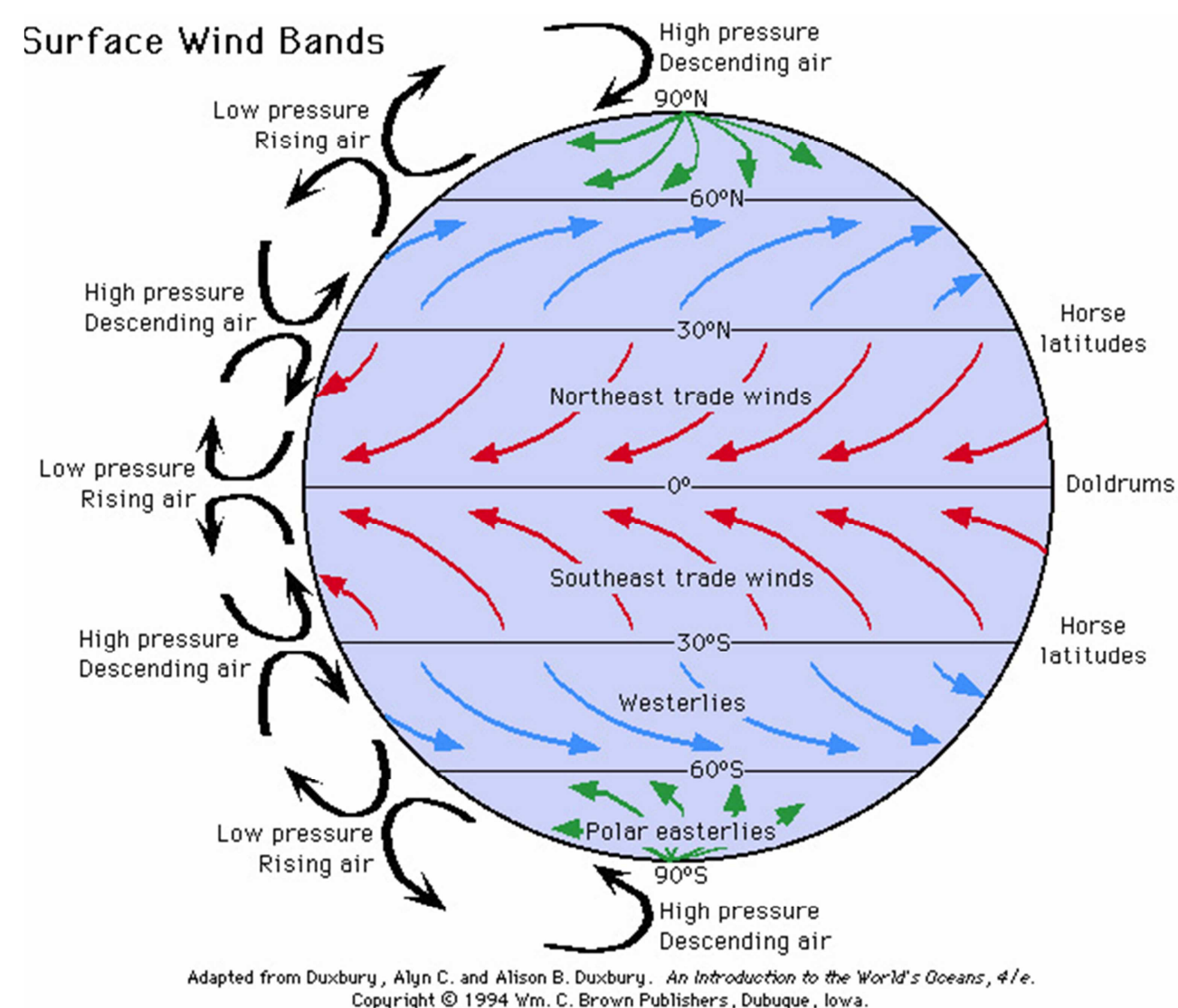

Figure 12. This is a schematic representation of the air currents that are constantly present in the Earth's atmosphere.

If the existence of the Lorentz force $\mathrm{F}_{\mathrm{L}}$ * is not in doubt, this suggests that the downward air currents are negatively charged. Thus, it is also natural to take for granted that the air that is constantly sinking in the 30-degree parallel northern hemisphere (Figure 12) is negatively charged and is thus an additional source of negative electrization in the Sargasso Sea.

Since these factors undoubtedly affect the electrization of the Sargasso Sea, their influence is useful to take into account both for a complete understanding of the nature of the phenomena occurring in its area, and for the prevention of sea and air accidents.

\section{Conclusion}

Powerful electromagnetic forces act both in the earth's atmosphere and on the earth's surface, including in the water. These forces distribute charges, moving positive charges up, and negative ones down. For this reason, positively charged earth objects receive additional lift, and negatively charged earth objects experience additional gravity. For the same reason, the buoyancy of positively charged ships and the lifting force of positively charged aircraft increase, and the buoyancy of negatively charged ships and the lifting force of negatively charged aircraft decrease.

The same electromagnetic forces of the Earth cause negative electrization of objects that are located in the northern hemisphere of the Earth and rotate clockwise in a horizontal plane. Thus, these forces create negative electrization of the Sargasso Sea, which is located in the northern hemisphere and is formed (limited) by sea currents moving clockwise. In addition, the same forces cause negative electrization of air over the Sargasso Sea, which also rotates clockwise. All this causes a negative electrization of ships and aircraft crossing the Sargasso Sea, which reduces their buoyancy and lift.

In addition, the negative electrization of the Sargasso Sea reduces the bearing capacity of its internal waters with respect to objects located on its water surface.

Moreover, the negative air electrization of the Sargasso Sea contributes to the appearance of nervous disorders and drowsiness in pilots and sailors.

Thus, negative electrization may be the main cause of the abnormality of the Sargasso Sea. (It should be noted that the abnormality of the Devil Sea, which is also located in the northern hemisphere and is created by numerous sea currents that rotate clockwise, can be of the same nature.).

Understanding the electromagnetic nature of the phenomena occurring in the anomalous zones allows us to suggest ways to reduce their destructive effects. Thus, it can be assumed that targeted positive electrization of ships sailing in anomalous zones will increase their buoyancy. It can also be assumed that the targeted positive electrization of aircraft flying in anomalous zones will increase their lift.

Apparently, all these arguments can also be true for cyclonic zones, the air and water of which, together with the 
objects located in them, receive negative charges when they rotate in the horizontal plane and when they interact with the geomagnetic field.

\section{References}

[1] Purcell E. M. (2011) Electricity and Magnetism in BPC, 2. NY: McGraw-Hill Education.

[2] Feynman R., Leighton R., Sands M. (1971) FLP, 3. Massachusetts: Addison Wesley Publishing Company.

[3] Pivovarenko Y. (2015) A Charge Distribution in the Earth's Atmosphere. American Journal of Physics and Applications, 3 (3), 67-68.

[4] Pivovarenko Y. (2018) The Nature of the Celestial Elves, Sprites and Jets. Discovery Nature, 12, 1-4.

[5] Pivovarenko Y. (2019) Earth's Electromagnetic Forces and Their Participation in the Creation of Tornadoes. American Journal of Electromagnetics and Applications, 7 (1), 8-12.

[6] Pivovarenko Y. (2017) The Flight of the Balloon and the Daily Rotation of the Earth. World Journal of Applied Physics, 2 (2), 32-35.

[7] Pivovarenko Y. (2017) The Significance of Positive Electrization on Lifting Force. American Journal of Aerospace Engineering, 4 (6), 59-62.

[8] Church C. R., Snow J. T. (1984) Measurements of Axial Pressures in Tornado-like Vortices. J. Atmos. Sci., 42 (6), 576582.

[9] Pauley R. L. (1989) Laboratory Measurements of Axial Pressures in Two-celled Tornado-like Vortices. J. Atmos. Sci., 46 (21), 3392-3399.
[10] Winn, W. P., Hunyady S. J., Aulich, G. D. (1999) Pressure at the Ground in a Large Tornado. J. Geophys. Res, 104 (18), 22067-22082.

[11] Edwards R., Ladue J. G., Ferree J. T., Scharfenberg K., Maier C., Coulbourne W. L. (2013) Tornado Intensity Estimation: Past, Present, and Future. Bulletin of the American Meteorological Society, 94 (5), 641-653.

[12] Seibold E., Berger W. H. (1996) The Sea Floor: An Introduction to Marine Geology.

[13] Kuznetsov V. V., Cherneva N. I., Druzhin G. I. (2007) On the Influence of Cyclones on the Atmospheric Electric Field of Kamchatka. Reports of the Academy of Sciences, 412 (4), 1-5.

[14] Pivovarenko Y. (2017) Potential-dependent changes of the surface tension of water. Fluid Mechanics, 3 (4), 29-32.

[15] Pivovarenko Y. (2018) \pm Water: Demonstration of water properties, depending on its electrical potential, World Journal of Applied Physics, 3 (1), 13-18.

[16] Harchenko N. V., Tchernenko V. V., Tchervak I. N., Stukalo V. M., Tokar D. V. (2008) Using Espumizan preparation in practice gastroenterologist. Ukraine's Health, 6 (1), 52-53. In Russian.

[17] Pivovarenko Y. (2018) The value of gaseous hydrogen generated by the intestinal microflora of human. Chapter 7 in Top 10 Contributions on Biomedical Sciences, 2-15. Hyderabad, India: Avid Science.

[18] Crawford F. (1968) Waves in BPC, 3. NY: McGraw-Hill Education.

[19] Pivovarenko Y. (2017) The Electrical Polarization of the Earth in Its Orbital Motion. World Journal of Applied Physics, 2 (4), 97-100. 